\title{
Plant extracts as an astounding remedy to anemia - A review
}

Upasana Saha, Purva Sudesh Dharwadkar, Susmita Sur, Vishaharini V. and Madhu Malleshappa*

School of Sciences, Department of Life Sciences, Garden City University, Bengaluru.

Received: 3/15/2018; Accepted: 3/19/2018

\begin{abstract}
Anemia is one of the most widespread nutritional deficiencies of blood which affect the populations of all ages throughout the world, children and adolescents being at a significantly higher risk for the condition. Medicinal plants have been a source of succor in the control of many diseases in developing countries and anemia is no exception. Treatment of anemia involves an iron-rich diet, iron and vitamin supplements. Iron supplements that are commercially available, if consumed too much of which can lead to circumstances like Hemochromatosis, Neurogenic Disorders and sometimes even cancer. In this study, extracts of different plants (Moringa oleifera, Psidium guajava, Cymbopogon citratus, and Trigonella foenum-graecum) were examined for their iron content to formulate some natural iron product to put forth as a solution to iron deficiency. The total iron content in the standard solution and samples of selected plant were obtained by phenanthroline method modified using analysis by absorption spectrophotometer. The spectrophotometric studies reveal the amount of iron content and hence the efficiency of the species in combatting anemia. Since these are natural sources, the food supplements designed from their extracts are expected to provide a solution to the disease without causing the harmful effects of the commercial iron supplements and also alongside provide other nutritional benefits to the individual.
\end{abstract}

Key words: Anemia, iron, deficiency, natural, extracts, supplements, disease, Moringa oleifera, Psidium guajava, Cymbopogon ciratus, Trigonella foenum-graecum, phenanthroline.

\section{Introduction}

Iron plays an important role in the formation of red blood cells and is a vital component of hemoglobin, the pigment which carries oxygen to the cells of the body and carbon dioxide away from them. It is also involved in the formation of another pigment myoglobin which stores oxygen in the muscle for use during exercise.

Iron deficiency most commonly results from inadequate diet or failure to absorb iron from the food. Vegetarians are more likely to suffer from iron deficiency because the high-fibre foods in their diet such as pulses and whole grains makes absorption difficult and also iron intake tends to be less than that of people who eat animal products. Non-vegetarians are less susceptible to iron deficiency as the iron in the red meat is readily accessible and easily absorbed by the body, which is not the case with some other iron-rich foods.

Iron deficiency leads to anemia, which is a symptom rather than a disease itself, it is indicated by general tiredness, breathlessness, headaches and dizziness. Iron deficiency anemia is one of the most widespread preventable nutritional problems in the world, despite the continuous implementation of global programs for its control. Globally $50 \%$ of anemia is attributed to iron deficiency and accounts for approximately 841,000 deaths annually worldwide ${ }^{1}$.

\section{${ }^{*}$ Corresponding Author:}

\section{Dr. Madhu Malleshappa,}

Associate Professor,

School Of Sciences, Department of Life Sciences,

Garden City University, Bangalore-560049, India.

E-mail: madhu.malleshappa@gardencitycollege.edu
India stands low on the list of nations dealing with problems arising out of iron deficiency-it is 170th among 180 countries ranked for anemia among women, 114th among 132 for stunting in children under five, and 120th among 130 for wasting in children under five, according to the Global Nutrition Report, 2016. In India alone $80 \%$ of women are iron deficient, both pregnant and nonpregnant. ${ }^{2}$

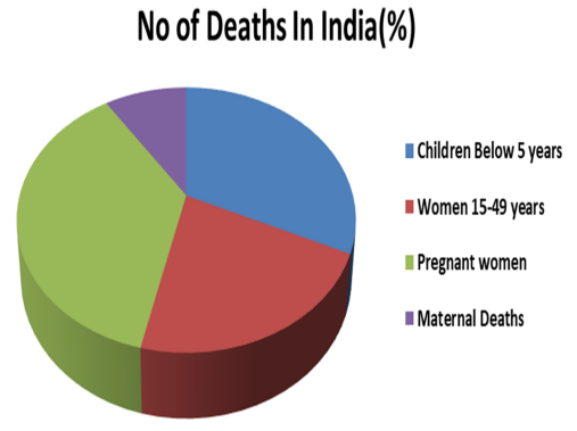

Figure 1. Rate of Deaths in India due to Iron Deficiency Anemia

Iron deficiency (ID) control programs have not been successful in reducing the number of iron deficient people in developing countries due to unsuccessful supplementation programs, the low absorption of some fortification iron compounds, and to the presence of other complicating health factors such as vitamin A deficiency. Although various drugs are available for the treatment of 
anemia, they are not often affordable to resourcepoor people, and not accessible to residents of remote areas. High quantity of consumption of these artificially produced commercial iron supplements can lead to health hazards like some neurogenic disorders and even cancer ${ }^{8}$.

Most iron-rich natural and nutritional sources are animalistic, which includes meat and liver. Usually the presence and bioavailability of iron from plant sources is lower. For this reason Vegans and Vegetarians are at particular risk of anemia. But studies show high iron content in plant sources like Drumstick leaves, spinach, lentils, dry fruits such as apricots and dates, beans and other pulses, guava, Methi, Lemongrass etc. Recent research is hence shifting focus towards such natural herbs and other plant parts or their extracts to produce remedies against a fast and wide spreading disease like Iron Deficiency Anemia.

As per United States Department of Agriculture (USDA) Food Composition Database Moringa olifera can provide up to $28 \mathrm{mg}$ of iron per $100 \mathrm{gms}$ of the leaves. It has also been reported that the iron content in Moringa is much higher than spinach $^{3}$. There is a paucity of literature regarding the beneficial effects of Moringa oleifera and jaggery in treating iron deficiency anaemia ${ }^{4}$.

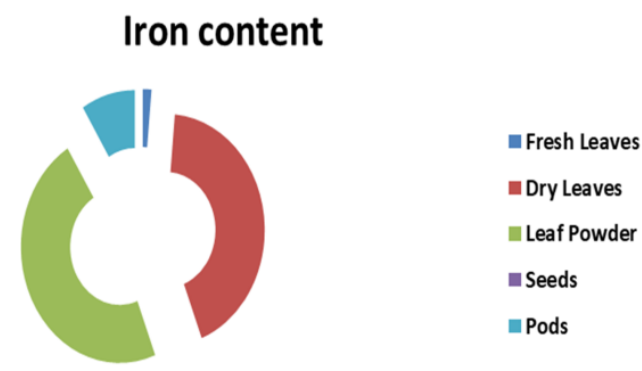

Figure 2. Iron content in Different parts of Moringa oleifera Lamk. plant (Data Source: Moringa oleifera: A review on nutritive importance and its medicinal application Lakshmipriya Gopalakrishnan ${ }^{b}$ Kruthi Doriya $^{a}$ Devarai Santhosh Kumar)

From the above graph it is very well observed that leaves of $M$. oleifera are the most powerful supplier of iron in every form. Thus in the current studies focus has been shifted to use the leaf extracts of this natural herb to design some solution towards iron deficiency anemia. M. oleifera is also rich in several phytochemicals like flavonoids, saponins, alkaloids and phenolic compounds in every part of the plant ${ }^{9}$ which are essential for iron take up and absorption by human body hence it can serve as a complete package of nutrition as well along with treatment against anemia.

The herb has been a useful source to treat fatigue, headaches, brain fag syndrome, breathing trouble etc. A combination of Moringa with jaggery has already been tried out as a solution to anemia and it has yielded positive results as well ${ }^{9}$. Now tests are to be conducted to use its leaf extracts solely as a natural iron supplement.

Trigonella foenum-graecum commonly known as Fenugreek of the pea family (Fabaceae) and also known as Greek hay, is another rich source of iron and as per United States Department of Agriculture (USDA) Food Composition Database provides 33.5 mg iron per $100 \mathrm{gms}$ of its leaves. Fenugreek leaves are great sources of iron and folic acid and work as effective foods for anaemia, to cure this condition. Spinach, fenugreek and dark green leafy vegetables are iron rich, help in red blood cell formation and increase the production of haemoglobin. Cooked, eaten raw or consumed as a health drink from the stock left behind once these leaves are boiled are excellent sources of iron for the body.

\section{Amount per teaspoon in \%DV}

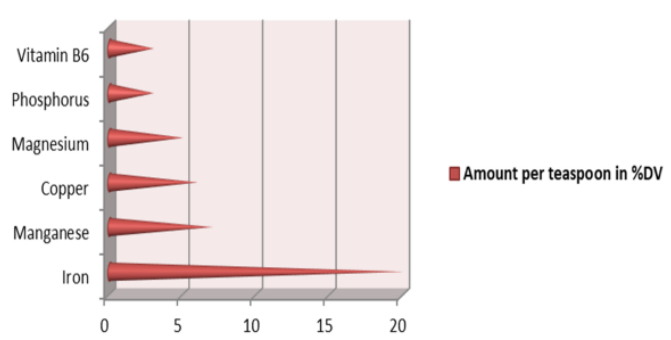

Figure 3. Different Mineral content in different parts of Trigonella foenum-graecum (Data Source: Dr Axe Food is medicine)

From the graph above it is predominant that Fenugreek has much more iron content than any other mineral or vitamin. Hence Fenugreek leaf extracts are also been tried upon as an aid to anemia in recent studies along with its already existing applications in treating digestive problems, inflammation, Libido, cholesterol level, promoting milk flow in breast feeding etc.

Another very common and easily available herb is Lemon Grass, (Botanical name-Cymbopogon citratus), from poaceae family. Though it is found commonly in tropical regions of Asia, it is native to India. Lemon grass has high medicinal value.

As per United States Department of Agriculture (USDA) Food Composition Database its iron content is as high as $8.2 \mathrm{mg}$ per 100 grams of its leaves and hence it helps in purification of blood and to increase the level of hemoglobin. 


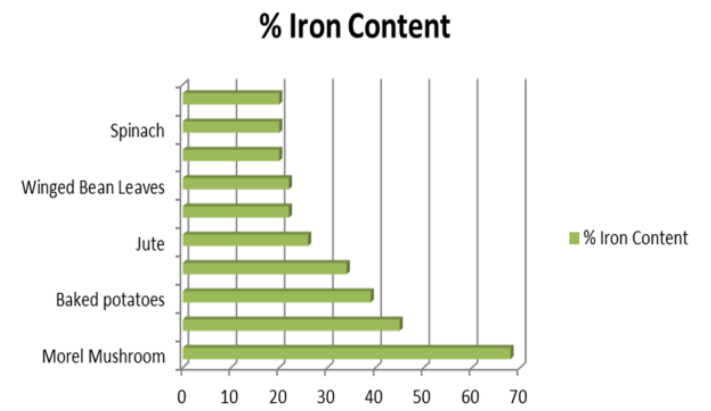

Figure 4. Iron content of various herbs when measured in percentage (Source: Daily Iron on your dinner plate)

As per the graph it is very clearly noted that when measured in percentage and compared with the best natural iron resources, lemongrass ranks second after Morel Mushrooms (68\%) in iron content $(45 \%)$. It is also rich in, flavonoids and phenolic compounds suitable for iron uptake by body. Although the herb has found its medicinal applications in treating various problems like headache, digestive tract, rheumatism, stimulating uterus and menstrual flow. Main components of the plant lemonal and citral have found their applications as anti-fungal and anti-microbial agents, has been used as flavoring agents in soaps and other cosmetic products and oil extracted from lemon grass has been used in aromatherapy for all pains; but this herb has not been focused on too much towards its contribution to treating iron deficiency Anemia. The literature shows clear view of its possibility towards the same and hence recent studies are been conducted to use it as a natural remedy to Anemia.

Psidium guajava popularly known as guava is a tree which is native to South America and is very popular in the Indian subcontinent as well. It has been used as a medicinal plant from past several years. Different parts of the tree have different pharmacological effects.

The leaves are rich in phenolic compounds, carotenoids, flavanoids, Gallic acid, catechin, the skin and bark contains glycoside, carotenoids and phenolic compounds. It is a rich source of vitamins, tannins, flavonoids, essential oils etc. The phenolic and alkaloid compounds present can be used to treat anemia. As per United States Department of Agriculture (USDA) Food Composition Database it provides $0.26 \mathrm{mg}$ iron for $100 \mathrm{~g}$ of leaves ${ }^{11,12,13,14}$.
AMOUNT IN GUAVA PER MG

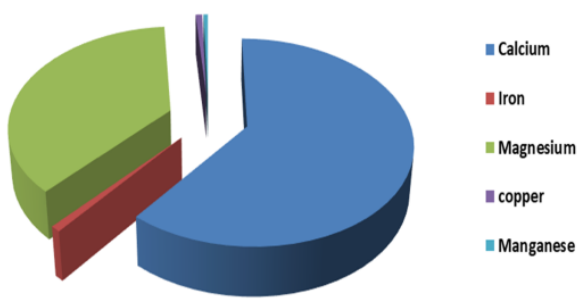

Figure 5. Different mineral content in guava [Data Source USDA]

The fruits can help in increasing the platelet cells in the patient suffering from dengue fever. Fruits and leaves have also shown a positive effect on the level of hemoglobin in anemic patients. The juice of guava leaves is taken as a medicine to treat anemia. In the studies carried out at the University of Calabar has proved that the leaves help in the formation of blood cells, increase in hemoglobin and is free of side effects ${ }^{10}$. Traditionally hence it is used as a potent drug to treat anemia and has been ranked first in its iron content and potency followed by Sweet potato leaves, Goat grass leaves and pumpkin leaves.

To be precise the most common plants available in the subcontinent showing a considerable amount of iron content has been neglected while finding a natural solution to anemia. Hence recent research needs to be focused on various parts of these plants that will surely reveal some great treatments to iron deficiency in the mere future.

\section{Materials and Methods}

Requirements for extract preparation:

a. Plant species: Moringa oleifera, Psidium guajava L., Trigonella foenum-graecum, Cymbopogon citratus

b. Chemicals: Conc. Hydrochloric Acid ( $\mathrm{HCl})$, Distilled water $\left(\mathrm{H}_{2} \mathrm{O}\right)$

c. Instrumentation: Muffle Furnace, Porcelain crucible, Weighing balance

d. Glasswares: Measuring Cylinder, Beakers, Filter paper. Glass Rod.

Requirements for quantitative estimation of iron content of the respective plant species by phenanthroline method

a. Extracts of the respective plant species prepared in experiment 1.

b. Chemicals: Hydrochlorate Hydroxylamine $\left(\mathrm{HONH}_{2} \cdot \mathrm{HCl}\right), \quad$ Sodium Acetate $\left(\mathrm{CH}_{3} \mathrm{COONa}\right)$, Acetic Acid $\left(\mathrm{CH}_{3} \mathrm{COOH}\right), \mathrm{O}-$ Phenanthroline $\left(\mathrm{C}_{36} \mathrm{H}_{24} \mathrm{FeN}_{6}{ }^{+2}\right)$ and Distilled water $\left(\mathrm{H}_{2} \mathrm{O}\right)$.

c. Instrumentation: Spectrophotometer, Weighing Balance

d. Glasswares: Beakers, Measuring cylinder, Pipettes, Test tubes, Glass Rod. 
Chemical Preparation:

a. Hydrochlorate Hydroxylamine: 10 grams of Hydrochlorate Hydroxylamine was dissolved in $50 \mathrm{ml}$ of distilled water.

b. Sodium Acetate Buffer: 8.5 grams of Sodium Acetate and $12 \mathrm{ml}$ of acetic acid were added to $88 \mathrm{ml}$ distilled water.

c. O- Phenanthroline: 0.1 grams of OPhenanthroline was dissolved in $80 \mathrm{ml}$ Distilled water at 80 degrees.

\section{Protocol for Extract Preparation}

I. 3 grams of plant species was weighed accurately using a weighing balance

II. The weighed sample was subjected to a dry wash in a Porcelain crucible at a temperature of 450 degrees in a muffle furnace for approx. 24 hours

III. The burnt plant samples were collected from the furnace and 0.3 grams of each species sample was dissolved in $5 \mathrm{ml}$ of concentrated $\mathrm{HCl}$ which precipitates all the impurities at the bottom of the crucible.

IV. The volume is made up to $50 \mathrm{ml}$ for each sample separately using distilled water.

V. The solution was filtered using filter paper twice.

VI. Thus the plant extracts were obtained for further studies

Protocol for quantitative estimation of iron content of the respective plant species by phenanthroline method

I. $1 \mathrm{ml}$ of each plant extract is measured and taken in a test tube

II. $1 \mathrm{ml}$ of Hydrochlorate Hydroxylamine is added to the extracts.

III. $2 \mathrm{ml}$ of Sodium acetate buffer followed by $2 \mathrm{ml}$ of $\mathrm{O}$ - phenanthroline was also added to it.

IV. The test tubes were incubated at room temperature for approx. 30 mins. Orange red complex is expected.

V. The absorbance was measured at $510 \mathrm{~nm}$ using spectrophotometer.

VI. This test was carried out in triplicates and the arithmetic mean of the readings of absorbance of each of the triplicate was calculated.

VII. The concentration of the iron content of each sample was calculated graphically using a standard curve by plotting the concentration of extract against the corresponding iron content.

\section{Calculation}

The final iron content is calculated for the extracts of all the concerned species and noted. The calibration curve is used for the calculation.

Iron content $(\mathrm{mg} / 100 \mathrm{~g})=(\mathrm{CxDF} \times 10 \times 100) / \mathrm{P}$

[C: Iron concentration of the sample, obtained from the calibration curve $\mathrm{g} / \mathrm{g}$ ) DF: Dilution Factor, P: Mass of ash (g)]

\section{Results}

Studies on the iron content of 30different plant species by the above protocol helped design 30 medical remedies for anemia for which no side effects were complained by individuals. Mostly the following plant parts produced the remedies: stem bark $(32 \%)$, leaves and stems (24\%), followed by the leaves $(21 \%)$, roots $(13 \%)$ and whole plants $(10 \%)$.

\section{Percentage}

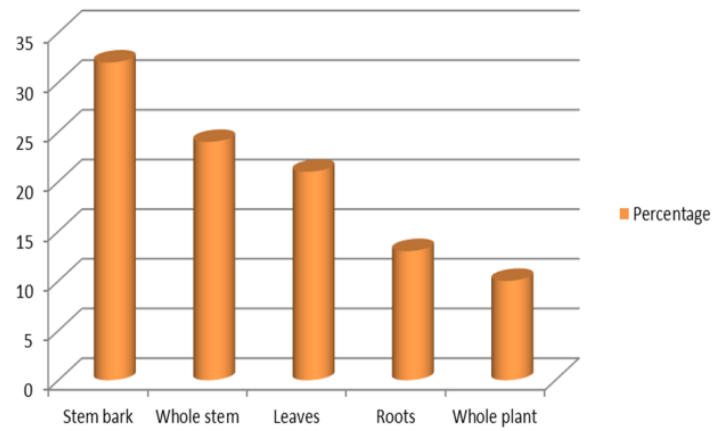

Figure 6. Parts of different plants useful in combating Iron Deficiency Anemia in studies

The most common plants studied for their iron content as a solution to the disease are noted below:

\begin{tabular}{lcc}
\hline Plant species & Organ Used & Content (mg/100 g) \\
\hline Amarantbus spinosus & Whole Plant & 236.6 \\
Cajanus cajan & Leaves and stems & 140 \\
Hoslundia opposita & Leaves and stems & 100 \\
Imperata cylindrica & Whole Plant & 170 \\
Justicia secunda & Leaves and stems & 26.6 \\
Khaya senegalensis & Stem Bark & 33.3 \\
Milicia excelsa & Stem Bark & 143.3 \\
Ricinus communis & Leaves and stems & 70 \\
Stylosanthes erecta & Leaves and stems & 206.6 \\
Tectona grandis & Leaves & 266.6 \\
Thalia geniculata & Whole Plant & 13.3
\end{tabular}

Table 1. Iron contents of studied plant species (Ref: Ethnomedical Study and Iron Content of Some Medicinal Herbs Used in TraditionalMedicine in Cote D'Ivoire for the Treatment of Anaemia; W Mamidou Koné, A G Koffi, E L Bomisso, and F H Tra Bi)

The four-species mentioned in these studies have shown considerable amount of iron content in their leaves. The iron content of all of them matches or is nearly similar to any one or more of the plant species studied above. Hence it is expected that conducting the same protocol on the extracts of these species will yield positive results and will produce excellent natural remedies for iron deficiency anemia.

\section{Discussion and Conclusion}

Anemia is very common in India as well as globally and its incidence is expected to increase in the mere future, there is need to prevent it or seek for more cost-effective and better treatment strategies for the same. Not much has been studied till date that can pinpoint natural and harmless remedy against the 
disease. The present study shows that the hemoglobin levels of the women in reproductive age group showed a significant improvement post intervention with Moringa oleifera and jaggery. This may be promoted in the community as a prophylactic and dietary supplementation in anemic women. The present study also concludes that Moringa oleifera effectively corrected hemoglobin levels in moderately anemic and included in the daily diet as a preventive and maintenance strategy for women. It should be given due consideration. Similar remedies can be designed with the other mentioned species also. It is necessary to formulate a complete natural remedy to fight against iron deficiency using these four-ignored species in mere future.

\section{Future prospects}

Iron plays a significant role in the hematopoiesis. However, the therapeutic potential of the herbs cannot be established on the basis of available iron content alone as other factors play a role in the absorption of iron in the body. Such factors are alkaloids, flavonoids, saponins, tannins, calcium, zinc, vitamins $\mathrm{C}$ and $\mathrm{K}$. Studies need to be conducted in mere future to design supplements that are not only high in iron content but also in alkaloids, flavonoids, saponins, tannins etc. so that body can include these also to fight anemia. Thus, we plan to design a complete solution to the disease using our plant extracts and supplementing them with the necessary phytochemicals so that this natural product can be made available to common masses to consume without any harmful side effects to them.

\section{Acknowledgement}

We would like to extend our heartiest gratitude to Dr. Joseph V. G, the honorary consul of the Republic of Maldives in Bangalore and chancellor Garden City University for his forever encouragement and support towards our endeavor. We would also like to thank Vice Chancellor, Principal, HOD and all the respected faculty members of School of Sciences, Garden City University, Bangalore.

\section{References}

1. Hill McGraw Iron deficiency and other hypo proliferative disorders. Harrison's text book of clinical medicine 18th edition, (2012)

2. Fuglie L.J., The Moringa Tree: A local solution to malnutrition Church World Service in Senegal; (2005)

3. Arcanjo FP, VP Pinto, MR Arcanjo, MR Amici, OM Amâncio. Effect of a beverage fortified with evaporated sugarcane juice on haemoglobin levels in preschool children. Rev Panam Salud Publica Vol 26 Issue (4).(2009); 350-4.
4. Mamidou Koné W, A G Koffi, E L Bomisso, and F H Tra B Ethnomedic al Study and Iron Content of Some Medicinal Herbs Used in Traditional Medicine in Cote D'Ivoire for the Treatment of Anaemia; Afr J Tradit Complement Altern Med. Vol 9 Issue(1) (2012) 81-87

5. Elangovan Malliga1*, M Dhanarajan. S2, Rajalakshmi A3, Jayachitra A 4, Pardhasaradhi Mathi4Narasimharao Bhogireddy4 Analysis of Phytochemicals, Antibacterial and Antioxidant activities of Moringa oleifera Lam. Leaf extract- an in vitro study; International Journal of Drug Development and Research.

6. Homnava A, W Rogers, R R Eitenmiller Provitamin A activity of specialty fruit marketed in the United States., J. Food Composition and Analysis Vol 3 (1990) pp.119-133

7. Wilberg V.C. D.B. Rodriguez-Amaya HPLC quantitation of major carotenoids of fresh and processed guava, mango and papaya, LebensmittelWissenschaft und-Technologie Vol 28 Issue 5 (1995) 474-480

8. Padula M, D.B. Rodriguez-Amaya Characteristics of the carotenoids and assessment of the vitamin $\mathrm{A}$ value of Brazilian guavas Food Chemistry Vol 20 (1986) 11-19

9. Ademola IO, BO Fagbemi, SO Idowu. Evaluation of the anthelmintic activity of Khaya senegalensis extract against gastrointestinal nematodes of sheep: in vitro and in vivo studies. Vet Parasitol. Vol 122 (2004) 151-164.

10. Akah P A, C E Okolo, A C Ezike. The haematinic activity of the methanol leaf extract of Brillantasia nitens Lindau (Acanthaceae) in rats. Afr J Biotechnol. Vol 82009 2389-2393.

11. Basta SS, MS Soekirman, D Karyadi, NS Scrimshaw. Iron deficiency anemia and the productivity of adult males in Indonesia. Am J Clin Nutr. Vol 32 (1979) 916-925.

12. Bruneton J. Pharmacognosie, Phytochimie et Plantes médicinales. 3e. Paris, France: TEC \& DOC et médicales internationales; (1999). 1120 p.

13. Crawley J. Reducing the burden of anemia in infants and young children in malaria-endemic countries of Africa: from evidence to action. Am J Trop Med Hyg. Vol 71(suppl 2) (2004) 25-34.

14. Edgerton VR, GW Gardner, Y Ohira, KA Gunawardena, B Swnewiratne. Iron-deficiency anaemia and its effect on worker productivity and activity patterns. Br Med J. Vol 2. (1979) 15461549.

15. Tahir A El, GM Sam, SA Khaud. Anti-plasmodial activity of selected Sudanese medical plants with emphasis on Maytenus senegalensis (Lam.) Exell. J Ethnopharmacol. Vol 64 (1999); 227-233.

16. Hedberg I. Botanical methods in ethnopharmacology and the need for conservation 
of medicinal plants. J Ethnopharmacol. Vol 38 (1983) 113-119.

17. Lebrun JP, AL Stork. Enumération des plantes à fleurs d'Afrique Tropicale: Monocotyledones: Liminocharitaceae à Poaceae Conservatoire et Jardin botaniques. Vol III. (1995).

18. Lozoff B, GM Brittenham, FE Viteri, AW Wolf, JJ Urrutia. The effects of short-term oral iron therapy on developmental deficits in iron-deficient anemic infants. J Paediatric. Vol 100 (1982) 351-357.

19. Moswa JL, N Kapanda, DM Mungende, W Okitolonda, M Mayangi, S Mihigo, K Mbale. Plants as an Important Source of Iron for the Treatment of Anaemia: Case of Justicia secunda; 11th NAPRECA Symposium Book of Proceedings; August 9-12; (2005). pp. 132-135.

20. Ogbe R J, G I Adoga, A H Abu. Antianaemic potentials of some plant extracts on phenyl hydrazine-induced anaemia in rabbits. J Med Plant Res. Vol 4 (2010) 680-684.

21. Omolo OJ, SC Chhabra, G Nyagah. Determination of iron content in different parts of herbs used traditionally for anaemia treatment in East Africa. J Ethnopharmacol. Vol 58 (1997) 97-102.

22. Pearson D. The chemical Analysis of foods Churchill Livingstone. 7th edn. (1976). p. 54.
23. Sanni FS, S Ibrahim, Esievo KAN, Effect of oral administration of aqueous extract of Khaya senegalensis stem bark on phenylhydrazine-induced anaemia in rats. Pak J Biol Sci. Vol 8 (2005) 255258.

24. Scholl TO, ML Hediger, RL Fischer, JW Shearer. Anemia vs. iron deficiency: increasedrisk of preterm delivery in a prospective study. Am J Clin Nutr. (1992) 985-988.

25. F. Asobayire Staubli. Development of a food fortification strategy to combat iron deficiency in the Ivory Coast. Zurich, Switzerland: Swiss Federal Institute of Technonogy; (2000). PhD Thesis. 239 p.

26. Waller DP. Methods inethnopharmacology. J Ethnopharmacol. Vol 38 (1983); 181-188.

27. WHO Scientific Group, author. Nutritional Anaemias. Geneva, Switzerland: WHO; (1968). (Tech Rep Ser No. 405).

\section{Cite this article as:}

Upasana Saha, Purva Sudesh Dharwadkar, Susmita Sur, Vishaharini V. and Madhu Malleshappa. Plant extracts as an astounding remedy to anemia; A review. Annals of Plant Sciences 7.4 (2018) pp. 2166-2171.

do $\mathrm{http://dx.doi.org/10.21746/aps.2018.7.4.16}$

Source of support: Garden City University, Bangalore

Conflict of interest: Nil 